\title{
Variations of NDVI and Its Association with Rainfall and Evapotranspiration over Bangladesh
}

\author{
Md. Monirul Islam* and Md. Mainul Islam Mamun \\ Department of Applied Physics \& Electronic Engineering, University of Rajshahi, \\ Rajshahi 6205, Bangladesh.
}

*Corresponding Author.rajib_apee@yahoo.com

\begin{abstract}
This paper deals with the variability of Normalized Difference Vegetation Index (NDVI) and its association with rain rate and total evapotranspiration over Bangladesh during the period of 2003-2011 using MODerate-resolution Imaging Spectroradiometer (MODIS), Tropical Rainfall Measuring Mission (TRMM) and Global Land Assimilation System (GLDAS) data. NDVI shows higher concentration in eastern parts of the country. The maximum NDVI is found in the month of October and minimum in February. It reveals excellent periodic variation in relation to rain rate and total evapotranspiration. NDVI shows strong spatial and temporal correlation with rain rate and total evapotranspiration especially in northwestern part of the country. Total evapotranspiration is more strongly correlated with vegetation than rain rate as it integrates rainfall, temperature and soil water statistics during the entire period. Thus, NDVI is an important variable for agronomical and climate applications. Also, it is important to study the vegetation for different seasons and different agro-ecological areas to investigate the variables affecting the vegetation types and growth rate.
\end{abstract}

Keywords-NDVI; Rainfall; Total Evapotranspiration; MODIS; TRMM; GLDAS; Bangladesh

\section{INTRODUCTION}

Nowadays advanced remote sensing has become a powerful monitoring tool for many aspects of global monitoring for its convenience and high efficiency. This technology has widely employed for descriptive and statistical studies between satellite derived vegetation conditions and various climatological variables over different regions with spatial and temporal scales [3]. Vegetation change plays a crucial role in the environmental process. Vegetation indices can serve as a sensitive indicator of climate and anthropogenic influences by altering energy balance, climate, hydrologic and biological cycles [11]. The Normalized Difference Vegetation Index (NDVI) is one of the most important and commonly used satellite-based vegetation indexes for monitoring vegetation changes and its interaction with various climatic variables to interpret its impact on biosphere [6]. NDVI is associated with a variety of vegetative parameters. The index is calculated from the following relation:

NDVI $=($ NIR - RED $) /($ NIR + RED $)$

Where NIR is the reflectance in the near-infrared channel and RED is the reflectance in the red channel. More than $90 \%$ of vegetation information is contained in these RED and NIR band [2]. The underlying principle of the above formula is that the radiation from visible red light is considerably absorbed (or poorly reflected) by chlorophyll in green plants, while the radiation from near infrared light is strongly reflected by the spongy mesophyll leaf stricter [15]. Environmental variations often alter the vegetation pattern. Precipitation is one of the most important parameters for vegetation growth [3]. Soil moisture is the crucial parameter for investigation of vegetation condition over a region. 
But over large geographical areas in situ information about soil moisture is difficult to obtain, where remote sensing precipitation information is a useful way at this circumstance as precipitation is the major natural source of soil moisture [3]. Evapotranspiration (ET) is another essential component for assessing vegetation dynamics as it plays crucial role in energy and water budget of grassland and agricultural ecosystem [1]. A large number of studies have conducted to assess the vegetation patterns over the world. Among the studies, [7] has showed a description of vegetation dynamics on a global scale; [17] carried out the spatial patterns of NDVI in response to precipitation and temperature in the Central Great Plains and [13] investigated interannual NDVI and its correlation to ET over northern Asia and reevent positive correlations were obtained between NDVI and interannual ET variation over vegetated regions. Although several studies have conducted over the world on interannual relationship among vegetation, rainfall and evapotranspiration but it is rather sparse in Bangladesh especially using remote sensing data. Therefore, the aim of this study is to investigate the spatial and temporal variation of NDVI over Bangladesh and its association with rainfall and ET response to interannual variability during the last decade.

\section{STUDY AREA}

The experimental area is Bangladesh located within the coordinates $20.5^{\circ} \mathrm{N}$ to $26.5^{\circ} \mathrm{N}$ and $87.5^{\circ} \mathrm{E}$ to $93.5^{\circ} \mathrm{E}$ (Fig.1). The total area of Bangladesh is $147,570 \mathrm{~km} 2$. The elevation is between the lowest point $0 \mathrm{~m}$ at Indian Ocean and the highest point $1052 \mathrm{~m}$ at Mowdoc range. Heavy rainfall is the characteristics of Bangladesh. The average rainfall of the country is about $1600 \mathrm{~mm}$ with a maximum of $5690 \mathrm{~mm}$ in the northeast and a minimum of $1110 \mathrm{~mm}$ in west. About $80 \%$ of total rainfall occurs during rainy season with a maximum in July. The average temperature of the country is about $25^{\circ} \mathrm{C}$. The maximum temperature in summer varies between $38^{\circ} \mathrm{C}$ to $41^{\circ} \mathrm{C}$. April is the hottest month of the country. There are four different vegetation areas in Bangladesh. The eastern zone which is consisted by the parts of Sylhet and Chittagong areas with low hills covered by jungles. The central zone which covers the parts of the north of Dhaka and supports swampy vegetation. The northwest and southwest zones consist mostly of cultivated plants and orchards whereas the southern zone along the Bay of Bengal contains wetlands with mangrove vegetation.

\section{Materials AND Methods}

MODerate-resolution Imaging Spectroradiometer NDVI data is used to analyze the vegetation over Bangladesh because it indicates the greenness of the surface which always signifies the presence of green plants. MODIS sensor onboard NASA's Terra and Aqua satellites have 36 spectral channels. NDVI is calculated from MODIS radiation data with a $5.6 \times 5.6 \mathrm{~km}$ spatial resolution. In this paper we use MODIS-Terra $0.05^{\circ} \mathrm{NDVI}$ level 3 monthly data products. MODIS provides the NDVI data with comparatively lower spatial resolution, but with a daily temporal resolution. This vegetation indices product is generated at $1^{\circ}$ spatial resolution from the $.05^{\circ}$ Climate Modeling Grid coverage product.

Tropical Rainfall Measuring Mission rain rate data is used for understanding the relationship of rainfall with vegetation. TRMM is a joint US-Japan satellite mission which is using to monitor the precipitation over tropical and subtropical areas. TRMM 3B43 V7 rainfall data product is used in this paper. 3B43 is used to produce the best estimation of rain rate in mmhr-1. It is version 7 data product with a spatial resolution of $25^{\circ} \times 25^{\circ}$. 
In this paper we have used the Global Land Assimilation System (GLDAS) for total evapotranspiration data which is simulated by the National Centers for Environmental Prediction/Oregon State University/Air Force/Hydrologic research Lab (NOAH) model. GLDAS is generating various land surface state and flux parameters from various land surface models. The GLDAS data has spatial resolution of $0.25^{\circ}$ and $1^{\circ}$, temporal resolution of 3-hourly and monthly, latitude extent between $-60^{\circ}$ to $90^{\circ}$ and longitude extent between $-180^{\circ}$ to $180^{\circ}$. NOAH is $1-\mathrm{D}$ column model which can be executed in either coupled or uncoupled mode. The model uses finite-difference spatial discretization methods with a Crank-Nicholson time integration scheme for numerical integration of the governing equations of physical processes of the soil-vegetation-snowpack medium. Monthly GLDAS NOAH10 M.001 data product is used which has a spatial resolution of $0.25^{\circ}$.

\section{RESULT AND DISCUSSION}

\section{A. Variation of NDVI}

The spatial distribution of NDVI in Bangladesh during the period of 2003-2013 is presented in Fig. 1. It can be seen that higher NDVI is observed in eastern parts of the country where relatively lower NDVI is observed in western parts. Chittagong and Sylhet divisions show highest NDVI during the last decade which indicates a more sustain climate for photosynthesis. Some regions in northwestern Rajshahi and Rangpur divisions along with a very small region in Sylhet division have experienced lower NDVI which may be due to any cataclysmic event or other human actions. Again in south, the coastal regions towards the Bay of Bengal report lower NDVI.

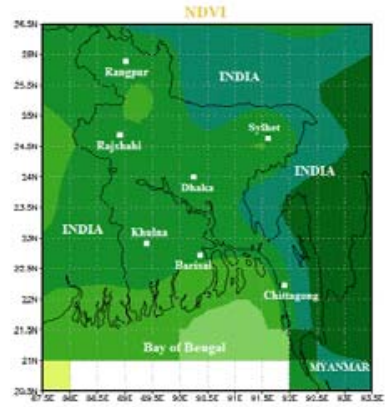

Fig. 1. Spatial distribution of annual means NDVI over Bangladesh for the period 2003-2011.

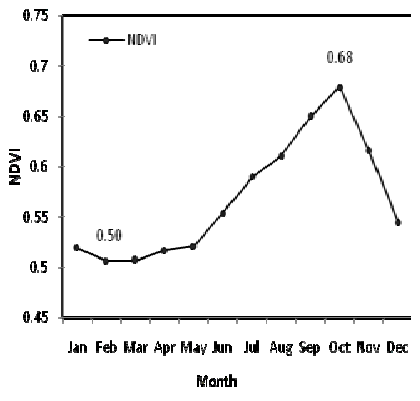

Fig. 2. Monthly mean variation of NDVI over Bangladesh.

Fig. 2 shows the monthly mean variation of NDVI over Bangladesh from the year 2003 to 2011. The monthly mean NDVI is obtained by averaging all the NDVI values in the same month during the period of 2003 to 2011 . The graphical presentation of the monthly mean NDVI reveals a fairly marked variation throughout the years. The minimum value $(0.50)$ of NDVI is observed in February which is rapidly increasing from the next month and become maximum (0.68) in October. After that the maximum NDVI is suddenly decreasing in November and this decreasing trend remains till to February. 


\section{B. Association of NDVI with Rainfall}

Water is crucial component for the growth of vegetation and hence the relation between the water availability and vegetation growth may be expected. Summer and winter rainfall show significant variations on different scales which have a strong impact on crops [8]. Due to the sequences on both spatial and temporal scale numerous studies attempted to discuss the relation between satellite based vegetation data and climate data [17]. [9] reports that the vegetation over India is decreasing during drought years while opposite results are shown during flood years. There are many studies done over Indian subcontinent on vegetation variability and its relation to meteorological parameters [5, 12]. In order to understand the association of NDVI with rain fall over Bangladesh interannual variations, spatial correlation, scatter plot and annual correlation analysis are observed.

Fig. 3 shows the interannual time series variations of NDVI and rain rate in Bangladesh from the year 2003 to 2011. It can be seen that NDVI and rain rate both show a good periodic variations throughout the study period. NDVI is increasing with rain rate from February and this increasing trend remains till to October while the increasing trends of rain rate remains till to July. During winter months NDVI and rain rate both report their minimum values. In general the higher NDVI is obtained in higher rain rate months. Therefore, NDVI is related to the water availability as higher vegetation is found during good rain rate receiving months but lower vegetation is found during poor rain rate receiving months.

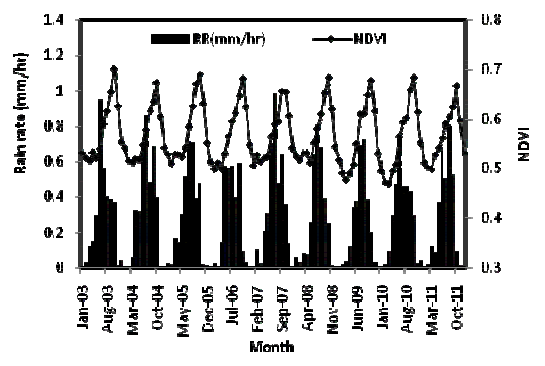

Fig. 3. Interannual variation (2003-20110) for NDVI and rain rate over Bangladesh.

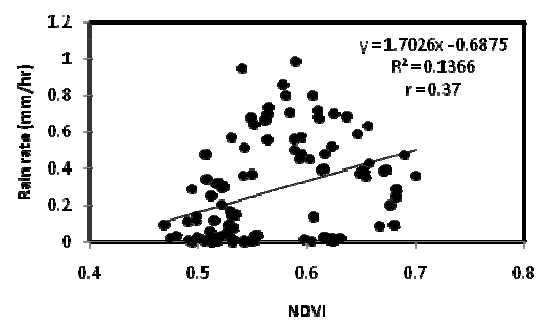

Fig. 5. The scatter plot of NDVI vs. rain rate over Bangladesh during the period 2003-2011.

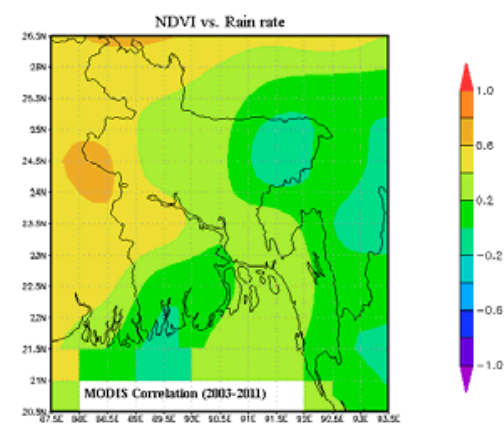

Fig. 4. Spatial correlation for NDVI vs. rain rate over Bangladesh for the period 2003-2011.

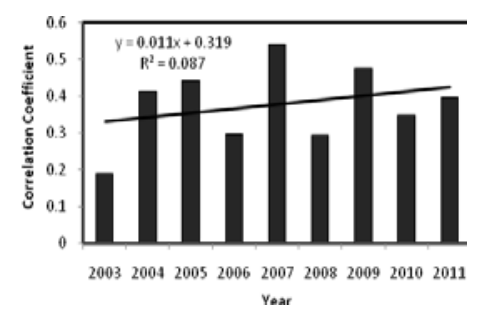

Fig. 6. Correlation coefficient between annual NDVI and rain rate over Bangladesh based on data for the period 2003-2011. 
Annual mean spatial correlation between NDVI and rain rate over Bangladesh for the period 2003 to 2011 is derived using MODIS remote sensing data as shown in Fig. 4. It can be seen from the spatial correlation map that in general a positive correlation is existed between NDVI and rain rate with a large variation across the country. The highest positive correlation is observed in northwestern region especially in Rajshahi division. The northeastern Sylhet division shows a negative correlation whereas the southeastern Chittagong division displays a very poor correlation tending to zero. Again the southern coastal regions toward the Bay of Bengal in conjunction with some areas of mangrove forest also exhibit negative correlations. It is known that western region especially Rajshahi division receives minimum rainfall where the eastern region especially Sylhet division receives maximum rainfall. Therefore, NDVI shows positive association in lower rainfall receiving regions whereas poor to negative correlation is found over higher rainfall receiving regions as precipitation is one of the major driving forces for vegetation growth.

Fig. 5 presents the scatter plots for NDVI vs. rain rate during the period of 2003 to 2011 . The scatter plot shows a positive correlation with a rate of 1.7 having a determination coefficient $\left(\mathrm{R}^{2}\right)$ of 0.14 . A gradually increasing interannual correlation between NDVI and rain rate from 2003 to 2011 is also shown in Fig. 6, where the slope and determination coefficient are 0.0116 and 0.0874 respectively. The interannual correlation shows a significant temporal variation which is always positive. The minimum correlation (0.19) is found in 2003 and the maximum (0.54) is found in maximum rain rate receiving year of 2007. The interannual rainfall variation leads the inteannual variations of correlation between NDVI and rain rate over the region.

\section{Association of NDVI with Evapotranspiration}

There are many research exhibited to establish relation between NDVI and evapotranspiration. NDVI has good correlation with evapotranspiration as NDVI is proportional to the vaporized water into the atmosphere $[4,10]$. This section deals with the relationship of NDVI with total evapotranspiration over Bangladesh through the use of interannual time series variation, spatial correlation, scatter plot and interannual correlation. Here, monthly basis MODIS data and GLDAS model data are used for the period 2003 to 2011.

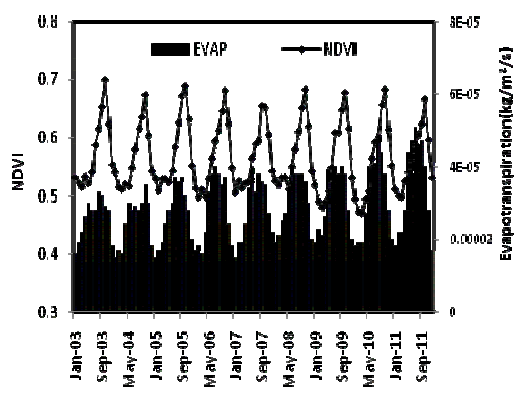

Fig. 7. Interannual variation (2003-20110) for NDVI and total evapotranspiration over Bangladesh.

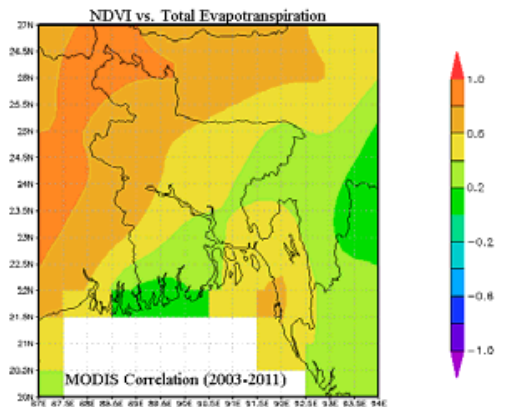

Fig. 8. Spatial correlation for NDVI vs. total evapotranspiration over Bangladesh for the period 2003-2011. 


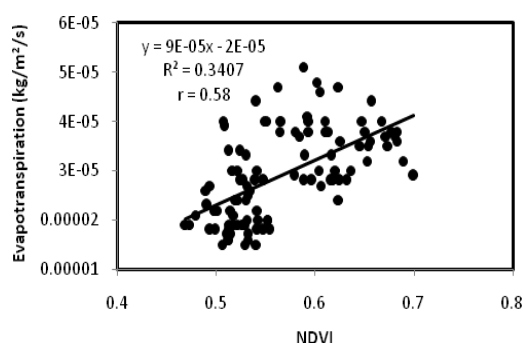

Fig. 9. The scatter plot of NDVI vs. total evapotranspiration over Bangladesh during the period 2003-2011.

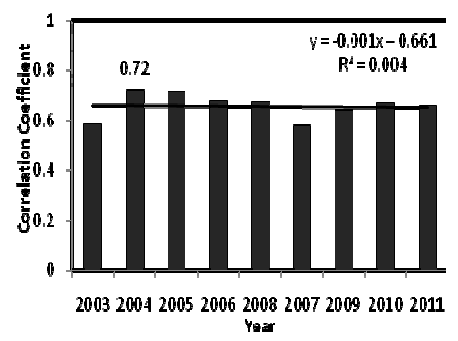

Fig. 10. Correlation coefficient between annual NDVI and total evapotranspiration over Bangladesh based on data for the period 2003-2011.

Fig. 7 presents the interannual time series variation of NDVI and total evapotranspiration. It can be seen that both NDVI and total evapotranspiration show an obvious similar periodic variation. Total evapotranspiration increases and reaches its top in August while NDVI arrive its highest in October. After that both of them rapidly decrease in winter months. Therefore, it seems that vegetation is strongly associated with evapotranspiration.

The spatial correlation between NDVI and total evapotranspiration is displayed in Fig. 8. A strong positive evident on spatial correlation between vegetation and evapotranspiration is observed over Bangladesh during the entire study period. The Northwestern region of the country especially Rangpur division reports higher positive correlation. This high positive correlation in northern part gradually decreases towards the southeast direction and the minimum correlation is found in the southern coastal region especially over mangrove forest in Khulna division. The northeastern Sylhet division also show a lower consistency but a higher relation exists in the Chittagong division.

Fig. 9 shows the scatter plot for NVDI vs. total evapotranspiration over Bangladesh for the duration 2003 to 2011. Here the slope, determination coefficient and correlation coefficient are $0.0009,0.3407$ and 0.58 respectively. The interannual correlation between NDVI and evapotranspiration from the year 2003 to 2011 over Bangladesh is also shown in Fig. 10. In this figure, a strong positive correlation with a slight declining rate of 0.0012 is found in all the years throughout the study period.

From the figures especially Fig. 5 and Fig. 9, it is clear that the NDVI has a strong correlation with the total evapotranspiration than the rain rate. Hence, NDVI index may be an effective tool for estimating evapotranspiration on regional scale, also may help to the modelers for model estimation by providing reference values of evaporation [14].

\section{CONCLUSION}

MODIS vegetation data, TRMM rain rate data and GLDAS evapotranspiration data are used to investigate the association of vegetation with rainfall and evapotranspiration over Bangladesh during the last decade. Spatial and temporal variations of vegetation are observed over Bangladesh. Eastern parts of the country show higher NDVI. The maximum NDVI is in October and minimum in February. The NDVI shows a good correlation with both rain rate and total evapotranspiration. It shows a good interannual 
periodic variation with rain rate and total evapotranspiration. NDVI is higher during good rainfall receiving months while it is lower during low rainfall receiving winter months. The vegetation increases with both rain rate and total evapotranspiration. The Northwestern parts of Bangladesh reveal highest spatial correlation of NDVI with rain rate and total evapotranspiration. NDVI show its highest spatial correlation with rain rate in northern Rajshahi division while with total evapotranspiration in northern Rangpur division. The higher rainfall receiving areas show lower correlation between NDVI and rain rate. The scatter plots report that the correlation coefficient of NDVI with rain rate is 0.37 and with total evapotranspiration is 0.58 . Vegetation is positively associated with both rain rate and total evapotranspiration in every year during the study period. The highest correlation coefficients of NDVI with rain rate are 0.54 in 2007 and with total evapotranspiration is 0.72 in 2004 . Total evapotranspiration shows best agreement with NDVI in correspondence with rain rate, possibly due to the fact that this variable integrates information of rainfall, temperature and water content of soil. This study is an attempt to analyze and monitor the relationships between vegetation, rainfall and evapotranspiration which can be consider a good step toward the study of climate-soilvegetation dynamics over Bangladesh.

\section{Acknowledgement}

The authors are thankful to NASA's MODIS, TRMM and GLDAS teams for providing the satellite data.

\section{References}

[1] Allen, R. G., Pereira, L. S., Raes, D. and Smith, M., “Crop evapotranspiration: guidelines for computing crop water requirements. Rome: Food and Agriculture Organization of the United Nations,” 300p. (Irrigation and Drainage, Paper 56). 1998.

[2] Baret, F., Guyot, G. and Major, D.J., “TSAVI: A vegetation index which minimizes soil brightness effects on LAI and APAR estimation, Proceedings of the 12th Canadian Symposium on Remote Sensing.” Vancouver ,Canada, pp. 1355-1358, 1989.

[3] Joanne M., Nightingale and Stuart R. Phinn, “Assessment of Relationships Between Precipitation and Satellite Derived Vegetation Condition Within South Australia,” Australian Geographical Studies, vol. 2, pp. 180-195, 1993.

[4] Kerr H., Imbernon J., Dedieu G., Hautecoeur O., Lagouarde J. P. and Seguin B., “NOAA AVHRR and its uses for rainfall and evapotranspiration monitoring," International Journal of Remote Sensing, vol. 10, pp. 847-854, 1989.

[5] Krishna Prasad, V., Badarinath, K.V.S. and Eaturu, A., "Effects of precipitation, temperature and topographic parameters on evergreen vegetation greenery in the Western Ghats, India," International Journal of Climatology, vol. 28, pp. 1807-1819, 2008.

[6] Lei S. and Bian Z., "Analysis of spatiotemporal difference of NDVI in an arid coal mining region using remote sensing,” In: Wagner W., Székely, B. (eds.): ISPRS TC VII Symposium 100 Years ISPRS, Vienna, Austria, IAPRS, Vol. XXXVIII, Part 7A, 2010.

[7] Moulin, S., Kergoat, L., Viovy, N. and Dedieu G., "Global-scale assessment of vegetation phenology using NOAA/AVHRR satellite measurements,” Journal of Climatology, vol. 10, pp. 1154-1170, 1997.

[8] Preethi, B. and Revadekar, J.V., "Kharif foodgrain yield and daily summer monsoon precipitation over India,” International Journal of Climatology, pp. 1-9, July 2012. 
[9] Revadekar, J.V., Tiwari, Y.K. and Ravi Kumar, K., "Impact of climate variability on NDVI over the Indian region during 1981-2010,” International Journal of Remote Sensing, vol. 33, pp. 7132-7150, doi.org/10.1080/ 01431161.2012.697642, 2012.

[10] Rossato L., Regina C. S. Alvala, Nelson J. Ferreira and Javier Tomasella, "Evapotranspiration estimation in the Brazil using NDVI data,” INPE ePrint: sid.inpe.br/ePrint@80, v1, 2005.

[11] Rousvel S., Armand K., Andre L., Tengeleng S., Alain T. S. and Armel K., "Comparison between Vegetation and Rainfall of Bioclimatic Ecoregions in Central Africa," Atmosphere, vol. 4, pp. 411-427, doi:10.3390/atmos4040411, 2013.

[12] Saikia, A., "NDVI variability in North East India,” Scottish Geographical Journal, vol. 125, pp. 195-213, 2009.

[13] Suzuki, R., Masuda, K., and Dennis, D.G., "Interannual covariability between actual evapotranspiration and PAL and GIMMS NDVIs of northern Asia," Remote Sensing of Environment, vol.106, pp. 387-398, 2007.

[14] Szilagyi J., Rundquist D. C. and Gosselin D. C., "NDVI relation to monthely evaporation," Geophysical Research Latters, vol. 20, pp. 1753-1756, 1998.

[15] Tucker, C.J., W.W. Newcomb, S.O. Los, and S.D. Prince, "Mean and inter-year variation of growing-season normalized difference vegetation index for the Sahel 1981-1989," International Journal of Remote Sensing, vol. 12, pp. 1113-1115, 1991.

[16] Wang, J., Price, K.P. and Rich, P.M., "Spatial patterns of NDVI in response to precipitation and temperature in the central Great Plains,” International Journal of Remote Sensing, vol. 22, pp. 1455-1467, 2000.

[17] Zhihui, G.U., Chen, J., Shi, P. and Ming, X.U., "Correlation analysis of Normalized Difference Vegetation Index (NDVI) difference series and climate variables in the Xilingole steppe, China from 1983 to 1999,” Frontiers of Biology in China, vol. 2, pp. 218-228, 2007. 